\title{
The TRAIL-receptor-1: TRAIL-receptor-3 and -4 ratio is a predictor for TRAIL sensitivity of cancer cells
}

\author{
CHIRLEI BÜNEKER, ANDREA MOHR and RALF MICHAEL ZWACKA \\ Molecular Therapeutics Group, National Centre for Biomedical Engineering Science, \\ National University of Ireland, Galway, Ireland
}

Received October 24, 2008; Accepted December 15, 2008

DOI: $10.3892 /$ or_00000353

\begin{abstract}
The tumour necrosis factor-related apoptosisinducing ligand (TRAIL) is a potent inducer of apoptosis in many cancer cells. However, a significant proportion of tumours are TRAIL-resistant erecting a major hurdle for a successful TRAIL-based treatment regimen in the future. In this context, it would be a major advantage to be able to identify the tumours that respond to TRAIL. The existence of two apoptosis-inducing receptors (TRAIL-R1 and TRAIL-R2) and two receptors that cannot transmit an apoptotic signal and have an inhibitory function (TRAIL-R3 and TRAIL-R4) make TRAIL signalling complicated. We analysed the surface expression of all four membrane-bound TRAIL receptors in cancer cell lines of various origin and primary cancer and normal cells and found a good correlation between TRAILsensitivity and the expression of TRAIL-R1 alone, but an even better correlation when a ratio of TRAIL-R1/TRAILR3+TRAIL-R4 was analysed. Experimental overexpression of TRAIL-R1 alone or in combination with TRAIL-R4 in PANC-1 cells confirmed our correlation results. Similar to the surface expression-apoptosis correlation analysis we found a high correlation between TRAIL-sensitivity and the mRNA level ratio of TRAIL-R1/TRAIL-R3+TRAIL-R4. A value of $<0.85$ for the ratio predicted TRAIL resistance in both protein and RNA analysis. Hence, TRAIL receptor RNA expression analysis by real-time PCR might be a feasible approach to predict possible TRAIL-responses in individual tumour samples.
\end{abstract}

\section{Introduction}

Tumour necrosis factor-related apoptosis-inducing ligand (TRAIL, also known as Apo-2L) is a member of the tumour

Correspondence to: Dr Ralf Zwacka, NCBES, National University of Ireland, Galway, University Road, Galway, Ireland

E-mail: ralf.zwacka@nuigalway.ie

Key words: apoptosis, tumour necrosis factor-related apoptosisinducing ligand, apoptosis-inducing ligand 2, tumour necrosis factor-related apoptosis-inducing ligand receptor, decoy receptor, real-time PCR necrosis factor family of cytokines and can selectively induce apoptosis in many cancer cells but not in most normal cells and has been proposed as a potential anti-tumour agent (1-5). TRAIL can bind to four membrane-bound death receptors (TRAIL-R1, TRAIL-R2, TRAIL-R3 and TRAIL-R4, also known as DR4, DR5, DcR1 and DcR2, respectively). Both TRAIL-R1 and TRAIL-R2 contain a conserved cytoplasmic region called the death-domain that is required for TRAIL induced apoptosis $(1,6,7)$. Upon activation of TRAIL-R 1 and TRAIL-R2 the adaptor protein Fasassociated death domain (FADD) is recruited to the receptors, which, along with procaspase- 8 , forms the deathinducing signalling complex (DISC) (8). Active caspase-8, the apical caspase in death receptor-induced apoptosis, can then activate effector caspases, such as caspase-3, which in turn cleave many cellular substrates resulting in the biochemical and morphological features characteristic of apoptosis $(9,10)$. However, TRAIL-R3 lacks an intracellular domain and TRAIL-R4 only contains a truncated deathdomain. Thus, TRAIL-R3 and TRAIL-R4 may protect cells from TRAIL-induced apoptosis by acting as decoy receptors $(6,11)$.

While TRAIL has shown remarkable promise as an anticancer agent, a significant fraction of tumour cells display TRAIL resistance (12-17). Different explanations have been suggested for this resistance. One hypothesis suggests the presence of decoy receptors (TRAIL-R3 and TRAIL-R4) that compete for binding to TRAIL $(11,18)$. The internal signalling pathway causing apoptosis after TRAIL treatment has been studied in detail, but the specific functions of the different TRAIL receptors on the surface of cancer cells and possible correlations with TRAIL responses are far less clear. Several studies (19-24) suggest that regulation of TRAIL-induced apoptosis is dependent on the expression of its various receptors. Therefore, the understanding of the regulation and function of each receptor during tumour progression is a prerequisite for the therapeutic application of TRAIL and might help to predict TRAIL responses of individual tumours, allowing for the more efficient use of TRAIL in clinical trials and beyond.

In the present study, we found a high correlation of the expression level ratio of TRAIL-R1/TRAIL-R3+TRAIL-R4 to TRAIL sensitivity. Because of this high correlation of the TRAIL receptor expression ratio and apoptosis, we propose this ratio as a potentially useful marker for predicting TRAIL responsiveness of tumours. 


\section{Materials and methods}

Reagents and cell lines. All reagents were purchased from Sigma (St. Louis, MO) unless otherwise stated. Human soluble recombinant TRAIL was purchased from R\&D Systems (Minneapolis, MN). The human cell lines PANC-1, Hek293 and HeLa were maintained in Dulbecco's modified Eagle's medium (DMEM). The cell line Caki-2, A549 and DLD-1 were cultured in RPMI-1640 medium. Caco-2 and the HCT116 were cultured in McCoy's medium. Media were supplemented with $10 \%$ fetal calf serum (FCS), $200 \mathrm{U} / \mathrm{ml}$ penicillin (P) and $200 \mu \mathrm{g} / \mathrm{ml}$ streptomycin (S). FCS and P/S were purchased from Biochrom (Berlin, Germany). All cell lines were cultured at $37^{\circ} \mathrm{C}$ and $5 \% \mathrm{CO}_{2}$. Colorectal carcinoma primary cells were collected from patients during surgery from University Hospital Galway. Samples were dissected into $1 \mathrm{x} 1 \mathrm{x} 1 \mathrm{~mm}$ pieces, immersed in a 10 -fold volume of RPMI-1640 containing $1.5 \mathrm{mg} / \mathrm{ml}$ collagenase, 5\% FCS and antibiotics and then incubated at $37^{\circ} \mathrm{C}$ overnight. The suspension containing released cells was then centrifuged at $150 \mathrm{x} \mathrm{g}$ for $5 \mathrm{~min}$. The precipitated cells were resuspended in culture medium [RPMI-1640, 25 mM Hepes, 5\% FCS, $50 \mathrm{nM}$ hydrocortisone, $20 \mu \mathrm{g} / \mathrm{ml}$ insulin, $10 \mu \mathrm{g} / \mathrm{ml}$ transferrin, $25 \mathrm{nM}$ sodium selenite, $1 \mathrm{ng} / \mathrm{ml}$ epidermal growth factor (EGF), $10 \mu \mathrm{M}$ ethanolamine, $10 \mu \mathrm{M}$ phosphorylethanolamine, $100 \mathrm{pM}$ triiodothyronine and $0.5 \mathrm{mM}$ sodium pyruvate] and seeded into collagen-coated culture flasks. MSCs were obtained through the Regenerative Medicine Institute at the National University of Ireland, Galway and grown, characterised and maintained, as previously described (25).

Measurement of apoptosis. For the detection of apoptotic cell death, standard DNA fragmentation assays according to Nicoletti et al (26) and Braeuer et al (27) were used. Untreated cells were taken as reference to calculate specific apoptosis by subtraction of the basal apoptosis values from the levels of treated cells.

Determination of the surface TRAIL receptor expression. TRAIL-R1 (HS 101), TRAIL-R2 (HS 201), TRAIL-R3 (HS 301) and TRAIL-R4 (HS 402) monoclonal antibodies (Alexis, Lausen, Switzerland) were used for FACS analyses of surface receptor expression, as previously described (28). Unspecific murine IgG1 was used as control for unspecific staining (isotype control).

Quantitative real-time PCR assays. Gene quantification was performed with a LightCycler (Roche Diagnostics, Mannheim, Germany) real-time PCR system. Total RNA was prepared from subconfluent cells using the RNeasy mini kit from Qiagen (Hilden, Germany). The primer-probe sets were designed with the GeneFisher software. Porphobilinogen Deaminase (PBGD) real-time PCR was used to normalise TRAIL-receptor data.

Statistical analyses. If not stated, three independent experiments were performed in triplicate. Experimental values are expressed as mean value \pm standard error (SE). Linear regression analyses were performed to examine the correlation between the resistance to TRAIL and the expression of the

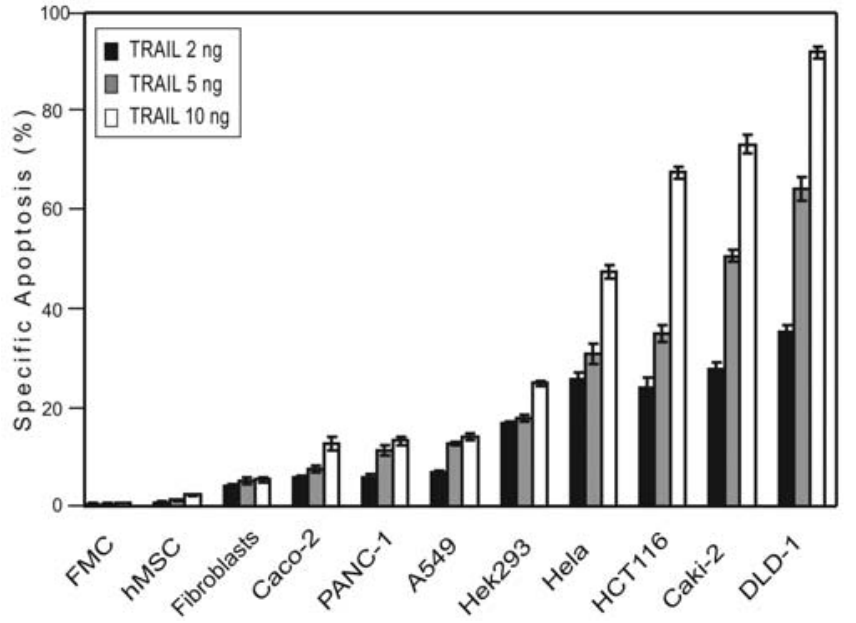

Figure 1. The indicated tumour cell lines were treated with 2, 5 and $10 \mathrm{ng} / \mathrm{ml}$ of soluble recombinant TRAIL for $24 \mathrm{~h}$, collected and analyzed for DNA content by DNA hypodiploidity assay. Percentages of cells with sub-G1 DNA content (= apoptotic cells) are shown.

TRAIL receptors. The correlation is expressed as $\mathrm{R}^{2}$. For significance analyses Student's t-tests, were used and $\mathrm{p}<0.05$ was considered significant and $\mathrm{p}<0.001$ as highly significant.

\section{Results}

TRAIL responsiveness varies among different tumour cell lines and primary (cancer) cells. Solid tumour cell lines of various tissue origins including colon cancer cell lines (HCT116, DLD-1, Caco-2), renal cancer cells (Caki-2), non-small lung cancer cells (A549), cervical cancer cells (HeLa) and pancreatic cancer cells (PANC-1) were used in this study. Furthermore, primary colon carcinoma cells (FMC), human mesenchymal stem cells (MSCs), human primary fibroblasts and transformed embryonic kidney cells (Hek293) were analysed. To evaluate the cell killing effect of TRAIL on these cells, they were treated with various concentrations $(2,5$ and $10 \mathrm{ng} / \mathrm{ml})$ of soluble recombinant TRAIL for $24 \mathrm{~h}$, after which the apoptotic response was measured (Fig. 1). Two cell lines (Caki-2, DLD-1) were highly sensitive to TRAIL-mediated cell death with $\geq 70 \%$ of the cells killed when challenged with $10 \mathrm{ng} / \mathrm{ml}$ of TRAIL. HeLa and HCT116 cells were sensitive with $\sim 50 \%$ of the cells killed. Hek293 cells were defined as moderate sensitive with apoptosis rates of 10-20\%. The other cell types (FMC, hMSC, fibroblasts, Caco-2, PANC-1, A549) were resistant to TRAIL-induced apoptosis. To see if the different TRAIL responsiveness could be attributed to their TRAILreceptor expression profiles, we analysed the protein expression of the four membrane-bound TRAIL receptors.

TRAIL responsiveness is correlated to the ratio of expression levels of TRAIL-1 and the sum of TRAIL-R3 and TRAIL-R4. In order to determine whether there is a correlation between TRAIL responsiveness and the expression levels of the four TRAIL-receptors, the surface protein expression levels of the four membrane-bound TRAIL receptors were analysed (Fig. 2A). Surface protein levels were determined by FACS measurements after staining with specific TRAIL receptor antibodies and a PE-labelled secondary antibody (Fig. 2A). 
A

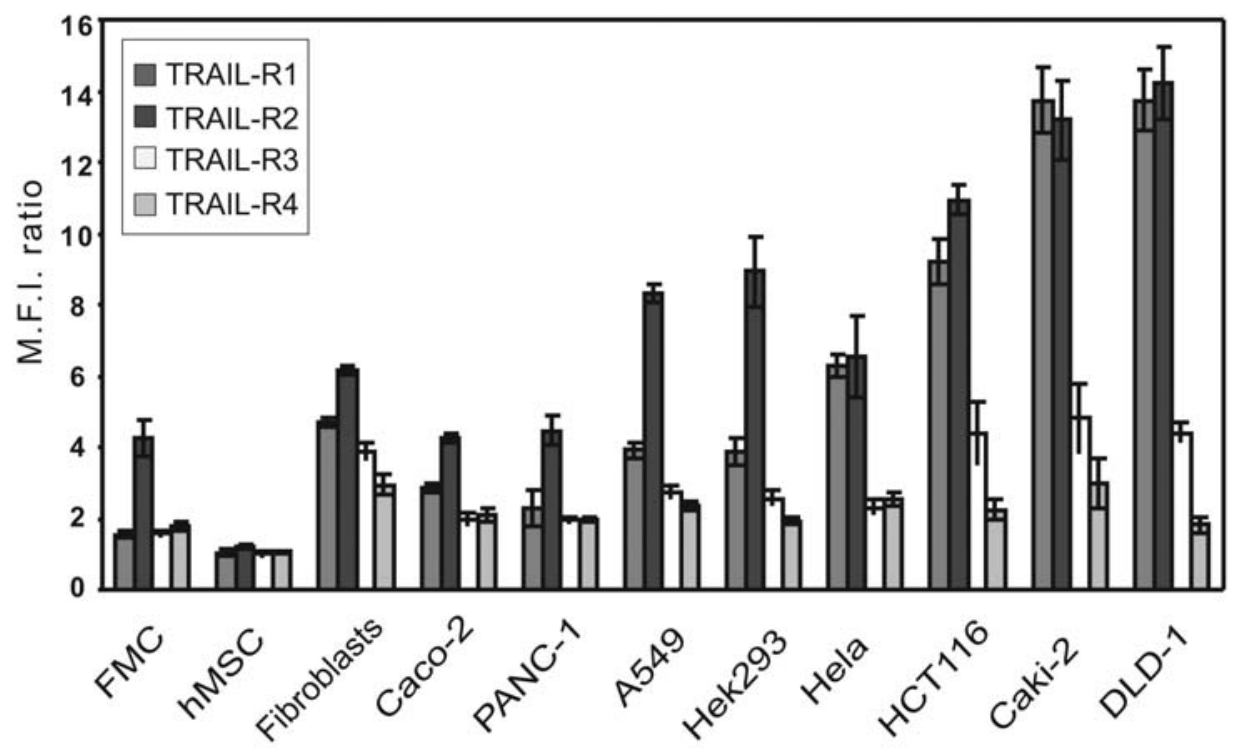

B

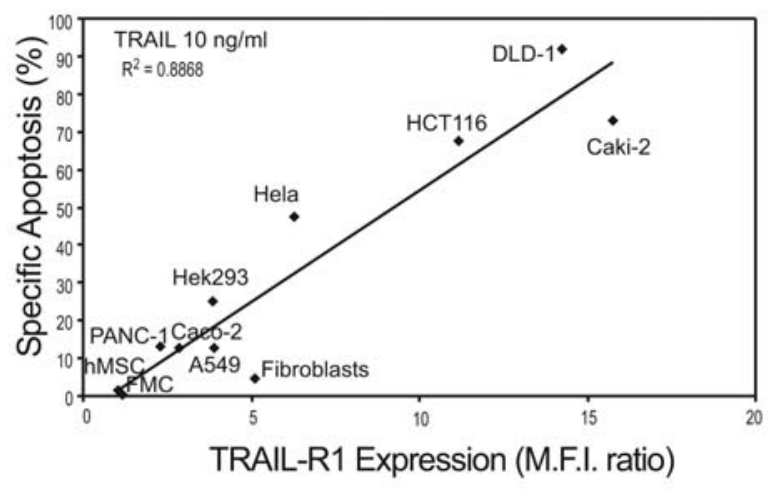

C

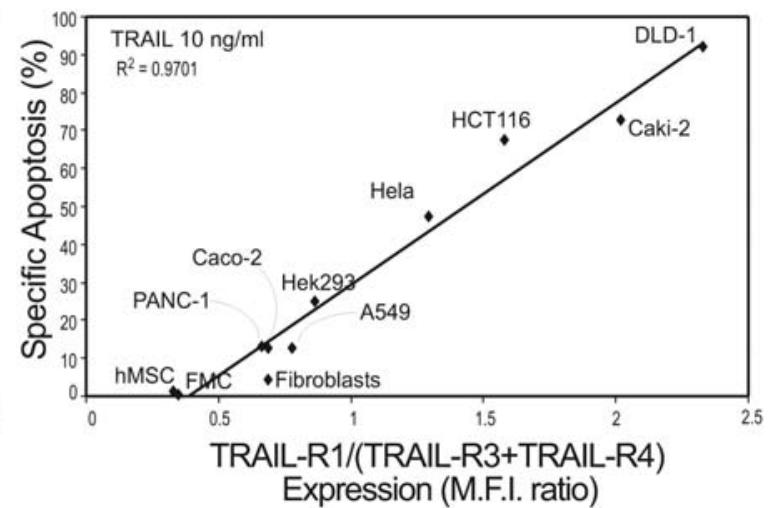

Figure 2. Analyses of the cell surface TRAIL receptor expression. (A) The levels of all four TRAIL receptors (TRAIL-R1, TRAIL-R2, TRAIL-R3, TRAIL-R4) were measured by FACS in the indicated cell lines and expressed as MFI ratio. (B) Regression analyses of TRAIL (10 ng/ml) responsiveness as expressed by apoptosis levels and the expression level of TRAIL-R1 expressed as MFI ratio. The squared correlation coefficient $\left(\mathrm{R}^{2}\right)$ is 0.8868 . $(\mathrm{C})$ This graph shows the correlation between TRAIL (10 ng/ml) sensitivity as expressed by apoptosis levels and the ratio of TRAIL-R1 MFI and the sum of the MFIs of antagonistic TRAIL receptors TRAIL-R3 and TRAIL-R4. The squared correlation coefficient $\left(\mathrm{R}^{2}\right)$ is 0.9701 .

We found varying TRAIL-receptor expression profiles, but TRAIL sensitivity seemed to correlate with the expression of the apoptosis-activating receptors TRAIL-R1, as the most sensitive cell lines (DLD-1 and Caki-2) had the highest expression levels of this receptor and the TRAIL-resistant cell lines such as PANC-1 showed very low expression levels of TRAIL-R1. However, A549 and Hek293 cells appeared to be outliers in this regard. Both cell lines harboured high TRAIL-R1, but were either TRAIL-resistant (A549) or showed only moderate TRAIL responsiveness (Hek293). To analyse this correlation in more detail we performed a regression analysis between the expression level of TRAIL-R1 and TRAIL responsiveness (10 $\mathrm{ng} / \mathrm{ml}$ TRAIL) of the cell lines tested (Fig. 2B). Despite the two outliers regression analysis confirmed a good correlation of TRAIL-R1 expression level with TRAIL responsiveness (Fig. 2B). Next, we tested whether inclusion of the decoy receptors would improve our regression analysis. Indeed, we arrived at an even higher correlation coefficient $\left(\mathrm{R}^{2}\right)$ using the ratio of TRAIL-R1 and the sum of the expression levels as expressed in MFI ratios of TRAIL-R3 and TRAIL-R4 (Fig. 2C). Overall, a ratio of $\leq 0.85$ for the MFI of TRAIL-R1 divided by the sum of the MFIs of TRAIL-R3 +TRAIL-R4 was found to be predictive for TRAIL resistance. Hence, the expression levels of the apoptosis-activating receptor TRAIL-R1 in relation to TRAIL-R3 and TRAIL-R4 appears to be predictive for the TRAIL responsiveness of cancer as well as normal cells.

Overexpression of TRAIL-R1 and TRAIL-R4 in PANC-1 cells. In order to confirm the correlation between the TRAIL sensitivity and the ratio of TRAIL receptor expression levels, we generated stable PANC-1 cell lines that overexpressed 
A

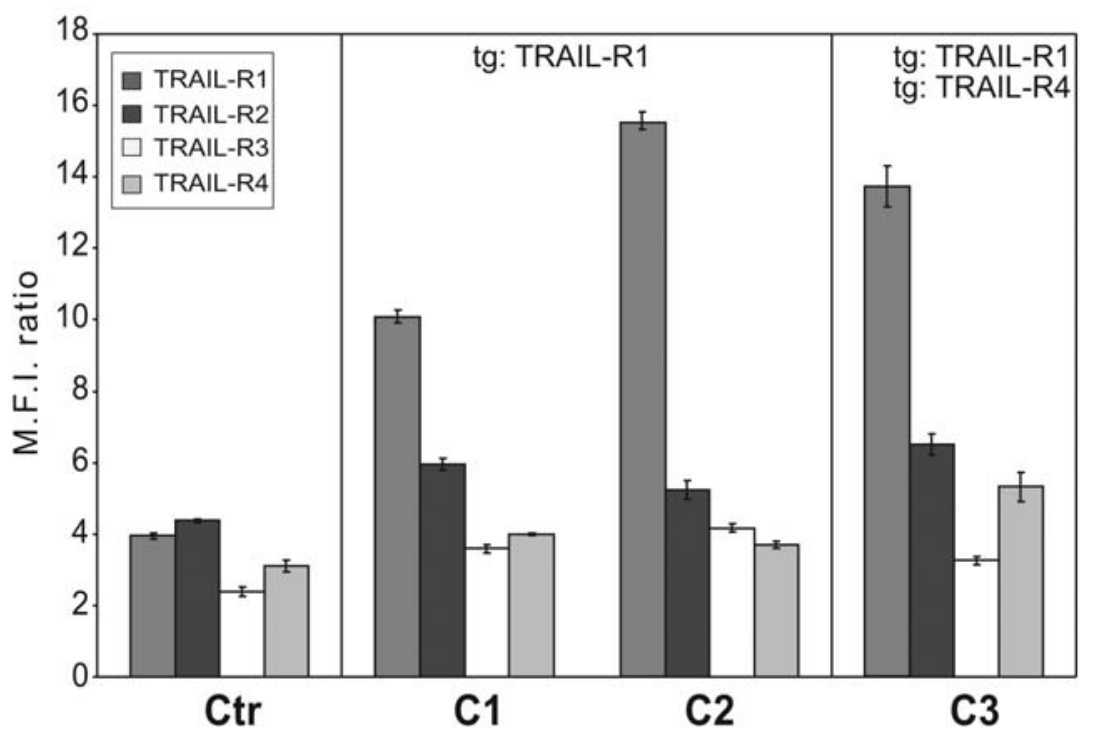

B

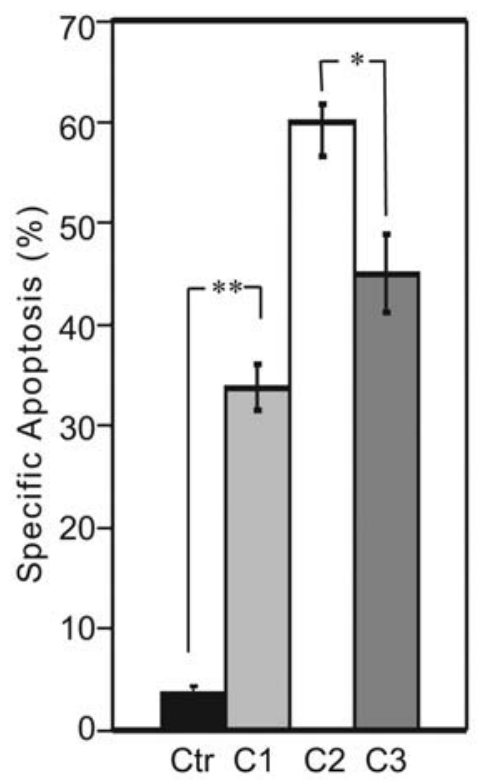

C

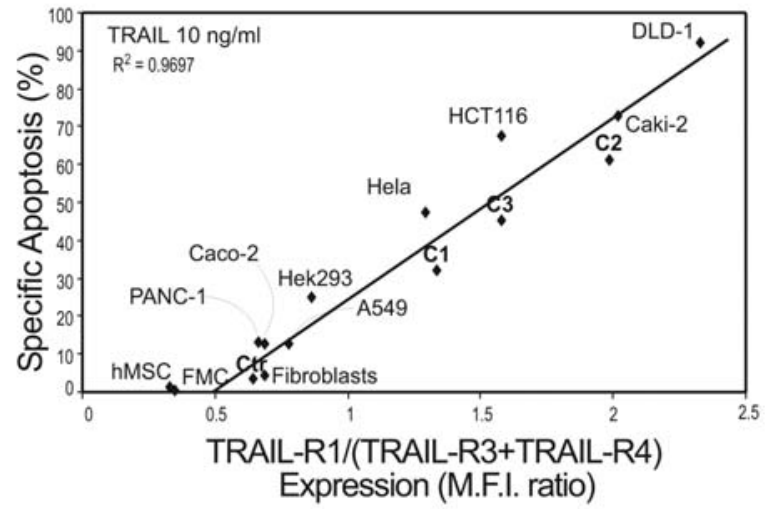

Figure 3. Analyses of the effect of TRAIL-R1 and TRAIL-R4 overexpression (transgene, $\operatorname{tg}$ ) on TRAIL responsiveness in pancreatic carcinoma cells PANC-1. (A) The levels of TRAIL receptors of two PANC-1 stable cells clones that overexpress TRAIL-R1 (C1, C2) and one stable cell clone, derived from C2 that cooverexpresses TRAIL-R1 and TRAIL-R4 (C3) were measured by FACS and expressed as MFI ratios. (B) Apoptosis assay after TRAIL treatment (10 ng/ml) from $\mathrm{C} 1, \mathrm{C} 2$ and $\mathrm{C} 3$ in comparison to parental PANC-1 cells, used as a control (Ctr). (C) Comparative regression analyses between apoptosis induced by TRAIL (10 ng/ml) and expression of TRAIL-R1 surface protein (MFI) divided by the sum of the antagonistic TRAIL-R3 and TRAIL-R4 expression (MFI) including the stable cell lines C1, C2 and C3. The squared correlation coefficient $\left(\mathrm{R}^{2}\right)$ is 0.9697 .

either TRAIL-R1 alone or together with TRAIL-R4. Protein expression of the TRAIL receptors was measured by FACS and we established two independent clones $(\mathrm{C} 1, \mathrm{C} 2)$ that overexpressed TRAIL-R1 to different levels (Fig. 3A). C2 was used to concurrently overexpress TRAIL-R4 resulting in clone 3 (C3) (Fig. 3A). Subsequently, we treated these clones as well as parental PANC-1 cells with TRAIL and measured apoptosis. The apoptosis assay revealed that $\mathrm{C} 1$ and $\mathrm{C} 2$ were TRAIL-sensitive with apoptosis rates of $35 \%$ (C1) to $60 \%$
(C2) (Fig. 3B). In C3 apoptosis was markedly reduced (45\%) as compared to its parental clone $\mathrm{C} 2(60 \%)$ owing to the moderate overexpression of TRAIL-R4 in C3. Next, we wanted to test whether these experimentally generated PANC-1 cell clones would also fit our correlation model. The correlation diagram including our original cell lines and primary cells as well as the three PANC-1 clones, C1, C2 and C3 confirm the relationship between TRAIL responsiveness and the expression levels of the TRAIL-R1, TRAIL-R3 and 


\section{A}

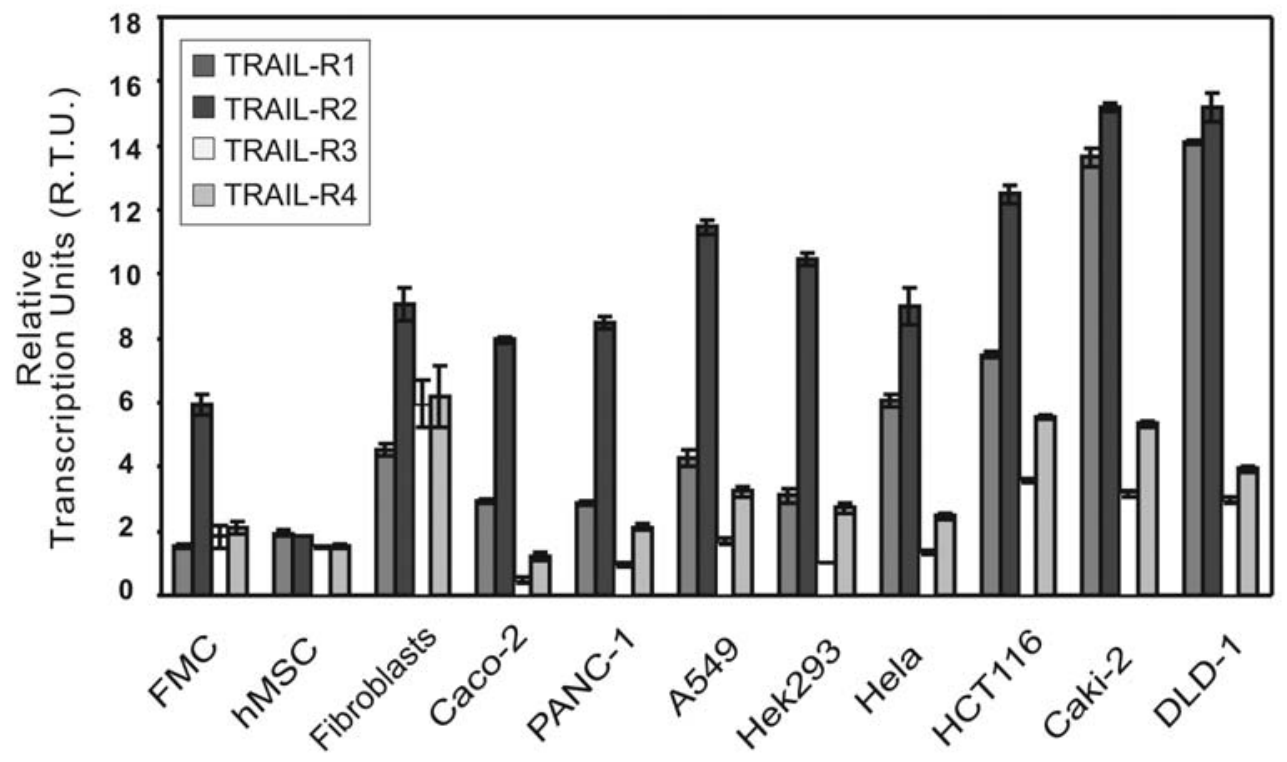

B

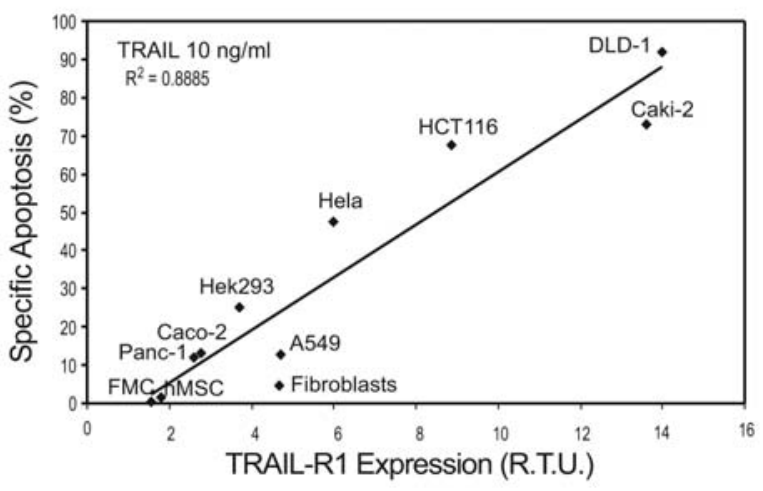

C

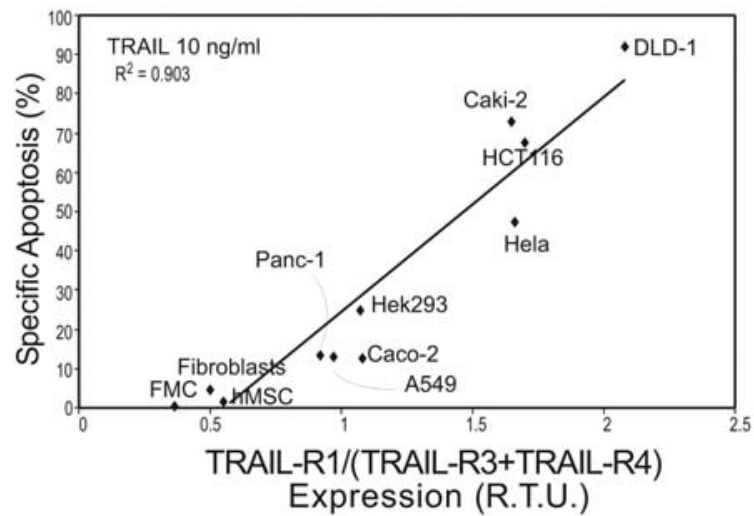

Figure 4. Real-time PCR analyses of TRAIL receptor expression. (A) The histogram shows the relative transcription units (RTU) of the four TRAIL receptors in the indicated cell types. (B) Regression analyses of TRAIL-R1 expressed as RTU and TRAIL responsiveness (10 ng/ml). The squared correlation coefficient $\left(\mathrm{R}^{2}\right)$ is 0.8885 . (C) This diagram shows the correlation between specific apoptosis and the RTU-ratio of TRAIL-R1 expression divided by the sum of TRAIL-R3 and TRAIL-R4 expression. The squared correlation coefficient $\left(\mathrm{R}^{2}\right)$ is 0.903 .

TRAIL-R4 (Fig. 3C). Hence, it appears possible to use this model to predict TRAIL sensitivity.

In a clinical setting it would probably be easier and more reliable to prepare RNA from tissue biopsies than to perform tissue staining with four different TRAIL receptor antibodies, while FACS analysis is unlikely to be a feasible option. Moreover, real-time PCR procedures can be automated and give rise to quantitative data. Therefore, we were interested in determining mRNA expression levels of the TRAIL receptors and compare them to surface protein expression levels.

Determination of $m R N A$ expression levels of TRAIL receptors by real-time PCR. Overall, the mRNA expression levels, as measured by real-time PCR, of the four TRAIL receptors were comparable to the surface protein expression levels (Fig. 4A). Again there was a good correlation of TRAIL-R1 expression and TRAIL sensitivity (Fig. 4B), but the ratio of TRAIL-R1/ (TRAIL-R3+TRAIL-R4) yielded an even better correlation coefficient (Fig 4C). Again, a factor of $<0.85$ for MFI TRAIL-R1/MFI TRAIL-R3+MFI TRAIL-R4 indicated TRAIL resistance. We conclude that TRAIL responsiveness is highly correlated to the expression of TRAIL-R1 as well as TRAIL-R3 and TRAIL-R4 and that quantitative RNA analysis by real-time PCR is a suitable method to measure and calculate a coefficient (TRAIL-R1/TRAIL-R3+TRAIL-R4) that can predict responsiveness to TRAIL.

\section{Discussion}

Resistance to TRAIL-induced apoptosis can occur at different levels in the TRAIL signalling cascade. One important factor that can lead to TRAIL resistance is the impaired or dysfunctional expression of TRAIL receptors. For example a 
death receptor malfunction due to genetic mutations $(29,30)$ or a lack of TRAIL-R1 and TRAIL-R2 expression (31) have been implicated in TRAIL resistance. In general, TRAIL binds to two cell-death-inducing (TRAIL-R1 and TRAIL-R2) and two decoy receptors (TRAIL-R3 and TRAIL-R4). However, the role of the decoy receptors in TRAIL-resistance is controversial. While several studies have highlighted their importance $(24,32-35)$, others have been unable to find a correlation between expression of TRAIL-R3 and/or TRAILR4 and TRAIL responsiveness (36-40). The complicating issue in these studies is that expression of decoy receptors is not the only molecular mechanism that can explain TRAIL resistance. In fact, several factors and pathways have been implicated in the inhibition of TRAIL-induced apoptosis (41). Thus, even in the absence of decoy receptors cancer cells can be TRAIL-resistant. Moreover, it appears likely that the ratio between the two death-inducing receptors on the one side and the two decoy receptors on the other is more important than the level of each individual receptor on its own. Therefore, we set out to investigate the expression of TRAIL receptors from eleven different cell types including cancer cell lines, primary colon carcinoma, fibroblastic cells and human MSCs. We found widely variable expression of the four TRAIL receptors. Nonetheless, our correlation analysis of TRAIL-receptor expression levels and TRAILinduced apoptosis levels revealed that in cancer cells lines as well as in primary cells including primary colon cancer cells the balance between death-inducing (TRAIL-R1) and deathprotecting TRAIL receptors (TRAIL-R3 and TRAIL-R4) is a determining factor for TRAIL responsiveness. Plotting our TRAIL receptor ratios (MFI of TRAIL-R1/MFI of TRAIL-R3 + MFI of TRAIL-R4) against the respective apoptosis levels we found the value that determines resistance of tumour cells to TRAIL cells to be $<0.85$. While it is clear that the TRAILreceptor expression profile is not the only determining factor for TRAIL responses, our approach can identify tumours that will definitely not benefit from TRAIL treatment. As we found that measuring TRAIL-receptor expression by real-time PCR was as good as TRAIL-receptor stains in our prediction model, real-time PCR analysis could be developed into a method to predict the tumour responsiveness to TRAIL.

\section{Acknowledgements}

This study was supported by an EC-FP6 Marie Curie Excellence grant. Andrea Mohr is supported by an HRB Post-doctoral fellowship. We thank Susanne Braeuer and Finbar McCarthy for their invaluable help.

\section{References}

1. Ashkenazi A, Pai RC, Fong S, Leung S, Lawrence DA, Marsters SA, Blackie C, Chang L, McMurtrey AE, Hebert A, DeForge L, Koumenis IL, Lewis D, Harris L, Bussiere J, Koeppen H, Shahrokh Z and Schwall RH: Safety and antitumor activity of recombinant soluble Apo2 ligand. J Clin Invest 104: $155-162,1999$

2. Wiley SR, Schooley K, Smolak PJ, Din WS, Huang CP, Nicholl JK, Sutherland GR, Smith TD, Rauch C and Smith CA: Identification and characterization of a new member of the TNF family that induces apoptosis. Immunity 3: 673-682, 1995.
3. Marsters SA, Sheridan JP, Donahue CJ, Pitti RM, Gray CL, Goddard AD, Bauer KD and Ashkenazi A: Apo-3, a new member of the tumor necrosis factor receptor family, contains a death domain and activates apoptosis and NF-kappa B. Curr Biol 6: 1669-1676, 1996.

4. Walczak H, Miller RE, Ariail K, Gliniak B, Griffith TS, Kubin M, Chin W, Jones J, Woodward A, Le T, Smith C, Smolak P, Goodwin RG, Rauch CT, Schuh JC and Lynch DH: Tumoricidal activity of tumor necrosis factor-related apoptosisinducing ligand in vivo. Nat Med 5: 157-163, 1999.

5. LeBlanc HN and Ashkenazi A: Apo2L/TRAIL and its death and decoy receptors. Cell Death Differ 10: 66-75, 2003.

6. Pan G, O'Rourke K, Chinnaiyan AM, Gentz R, Ebner R, Ni J and Dixit VM: The receptor for the cytotoxic ligand TRAIL. Science 276: 111-113, 1997.

7. Pan G, Ni J, Wei YF, Yu G, Gentz R and Dixit VM: An antagonist decoy receptor and a death domain-containing receptor for TRAIL. Science 277: 815-818, 1997.

8. Ashkenazi A: Targeting death and decoy receptors of the tumournecrosis factor superfamily. Nat Rev Cancer 2: 420-430, 2002.

9. Bratton SB, MacFarlane M, Cain K and Cohen GM: Protein complexes activate distinct caspase cascades in death receptor and stress-induced apoptosis. Exp Cell Res 256: 27-33, 2000.

10. Srivastava RK: Intracellular mechanisms of TRAIL and its role in cancer therapy. Mol Cell Biol Res Commun 4: 67-75, 2000.

11. Sheridan JP, Marsters SA, Pitti RM, Gurney A, Skubatch M, Baldwin D, Ramakrishnan L, Gray CL, Baker K, Wood WI, Goddard AD, Godowski P and Ashkenazi A: Control of TRAILinduced apoptosis by a family of signaling and decoy receptors. Science 277: 818-821, 1997.

12. Greco FA, Bonomi P, Crawford J, Kelly K, Oh Y, Halpern W, Lo L, Gallant G and Klein J: Phase 2 study of mapatumumab, a fully human agonistic monoclonal antibody which targets and activates the TRAIL receptor-1, in patients with advanced non-small cell lung cancer. Lung Cancer 61: 82-90, 2008.

13. Griffith TS and Lynch DH: TRAIL: a molecule with multiple receptors and control mechanisms. Curr Opin Immunol 10: 559-563, 1998.

14. Henson ES, Johnston JB and Gibson SB: The role of TRAIL death receptors in the treatment of hematological malignancies. Leuk Lymphoma 49: 27-35, 2008.

15. Humphreys RC and Halpern W: Trail receptors: targets for cancer therapy. Adv Exp Med Biol 615: 127-158, 2008.

16. Ndozangue-Touriguine O, Sebbagh M, Merino D, Micheau O, Bertoglio $\mathrm{J}$ and Breard $\mathrm{J}$ : A mitochondrial block and expression of XIAP lead to resistance to TRAIL-induced apoptosis during progression to metastasis of a colon carcinoma. Oncogene 27: 6012-6022, 2008

17. Thorburn A, Behbakht $\mathrm{K}$ and Ford H: TRAIL receptor-targeted therapeutics: resistance mechanisms and strategies to avoid them. Drug Resist Updat 11: 17-24, 2008.

18. Srivastava RK: TRAIL/Apo-2L: mechanisms and clinical applications in cancer. Neoplasia 3: 535-546, 2001.

19. French LE and Tschopp J: Inhibition of death receptor signaling by FLICE-inhibitory protein as a mechanism for immune escape of tumors. J Exp Med 190: 891-894, 1999.

20. Lacour S, Hammann A, Wotawa A, Corcos L, Solary E and Dimanche-Boitrel MT: Anticancer agents sensitize tumor cells to tumor necrosis factor-related apoptosis-inducing ligandmediated caspase-8 activation and apoptosis. Cancer Res 61: 1645-1651, 2001

21. Mongkolsapaya J, Cowper AE, Xu XN, Morris G, McMichael AJ, Bell JI and Screaton GR: Lymphocyte inhibitor of TRAIL (TNF-related apoptosis-inducing ligand): a new receptor protecting lymphocytes from the death ligand TRAIL. J Immunol 160: 3-6, 1998.

22. Ma YF, Zhang J, Zhao YP, Yang DL and Chen YH: Correlation between sensitivity to TRAIL and expression level of DR5 on surface of tumor cells. Zhonghua Zhong Liu Za Zhi 26: 528-530, 2004.

23. Hesry V, Piquet-Pellorce C, Travert M, Donaghy L, Jegou B, Patard JJ and Guillaudeux T: Sensitivity of prostate cells to TRAIL-induced apoptosis increases with tumor progression: DR5 and caspase 8 are key players. Prostate 66: 987-995, 2006.

24. Aydin C, Sanlioglu AD, Karacay B, Ozbilim G, Dertsiz L, Ozbudak O, Akdis CA and Sanlioglu S: Decoy receptor-2 small interfering RNA (siRNA) strategy employing three different siRNA constructs in combination defeats adenovirus-transferred tumor necrosis factor-related apoptosis-inducing ligand resistance in lung cancer cells. Hum Gene Ther 18: 39-50, 2007. 
25. Mohr A, Lyons M, Deedigan L, Harte T, Shaw G, Howard L, Barry F, O'Brien T and Zwacka R: Mesenchymal Stem Cells expressing TRAIL lead to tumour growth inhibition in an experimental lung cancer model. J Cell Mol Med (In press).

26. Nicoletti I, Migliorati G, Pagliacci MC, Grignani F and Riccardi C: A rapid and simple method for measuring thymocyte apoptosis by propidium iodide staining and flow cytometry. J Immunol Methods 139: 271-279, 1991.

27. Braeuer SJ, Buneker C, Mohr A and Zwacka RM: Constitutively activated nuclear factor-kappaB, but not induced NF-kappaB, leads to TRAIL resistance by up-regulation of X-linked inhibitor of apoptosis protein in human cancer cells. Mol Cancer Res 4: 715-728, 2006

28. Mohr A, Buneker C, Gough RP and Zwacka RM: MnSOD protects colorectal cancer cells from TRAIL-induced apoptosis by inhibition of Smac/DIABLO release. Oncogene 27: 763-774, 2008.

29. Lee SH, Shin MS, Kim HS, Lee HK, Park WS, Kim SY, Lee JH, Han SY, Park JY, Oh RR, Jang JJ, Han JY, Lee JY and Yoo NJ: Alterations of the DR5/TRAIL receptor 2 gene in non-small cell lung cancers. Cancer Res 59: 5683-5686, 1999.

30. Ozoren N, Fisher MJ, Kim K, Liu CX, Genin A, Shifman Y, Dicker DT, Spinner NB, Lisitsyn NA and El Deiry WS: Homozygous deletion of the death receptor DR4 gene in a nasopharyngeal cancer cell line is associated with TRAIL resistance. Int J Oncol 16: 917-925, 2000.

31. Horak P, Pils D, Haller G, Pribill I, Roessler M, Tomek S, Horvat R, Zeillinger R, Zielinski C and Krainer M: Contribution of epigenetic silencing of tumor necrosis factor-related apoptosis inducing ligand receptor 1 (DR4) to TRAIL resistance and ovarian cancer. Mol Cancer Res 3: 335-343, 2005.

32. Koksal IT, Sanlioglu AD, Karacay B, Griffith TS and Sanlioglu S: Tumor necrosis factor-related apoptosis inducing ligand-R4 decoy receptor expression is correlated with high Gleason scores, prostate-specific antigen recurrence, and decreased survival in patients with prostate carcinoma. Urol Oncol 26: 158-165, 2008

33. Hornstein M, Hoffmann MJ, Alexa A, Yamanaka M, Muller M, Jung V, Rahnenfuhrer J and Schulz WA: Protein phosphatase and TRAIL receptor genes as new candidate tumor genes on chromosome 8p in prostate cancer. Cancer Genomics Proteomics 5: 123-136, 2008.
34. Bouralexis S, Findlay DM, Atkins GJ, Labrinidis A, Hay S and Evdokiou A: Progressive resistance of BTK-143 osteosarcoma cells to Apo2L/TRAIL-induced apoptosis is mediated by acquisition of DcR2/TRAIL-R4 expression: resensitisation with chemotherapy. Br J Cancer 89: 206-214, 2003.

35. Riccioni R, Pasquini L, Mariani G, Saulle E, Rossini A, Diverio D, Pelosi E, Vitale A, Chierichini A, Cedrone M, Foa R, Lo CF, Peschle C and Testa U: TRAIL decoy receptors mediate resistance of acute myeloid leukemia cells to TRAIL. Haematologica 90: 612-624, 2005.

36. Strater J, Hinz U, Walczak H, Mechtersheimer G, Koretz K, Herfarth C, Moller P and Lehnert T: Expression of TRAIL and TRAIL receptors in colon carcinoma: TRAIL-R 1 is an independent prognostic parameter. Clin Cancer Res 8: 3734-3740, 2002.

37. Locklin RM, Federici E, Espina B, Hulley PA, Russell RG and Edwards CM: Selective targeting of death receptor 5 circumvents resistance of MG-63 osteosarcoma cells to TRAIL-induced apoptosis. Mol Cancer Ther 6: 3219-3228, 2007.

38. Deligezer U and Dalay N: Expression of the TRAIL receptors in blood mononuclear cells in leukemia. Pathol Oncol Res 13: 290-294, 2007.

39. Lincz LF, Yeh TX and Spencer A: TRAIL-induced eradication of primary tumour cells from multiple myeloma patient bone marrows is not related to TRAIL receptor expression or prior chemotherapy. Leukemia 15: 1650-1657, 2001.

40. Wuchter C, Krappmann D, Cai Z, Ruppert V, Scheidereit C, Dorken B, Ludwig WD and Karawajew L: In vitro susceptibility to TRAIL-induced apoptosis of acute leukemia cells in the context of TRAIL receptor gene expression and constitutive NF-kappa B activity. Leukemia 15: 921-928, 2001.

41. Kruyt FA: TRAIL and cancer therapy. Cancer Lett 263: 14-25, 2008. 